Iibrary, N.W. Bldg

SEP $6 \quad 1963$

\title{
NBS
}

Eechnical Note

195

\section{REPORT ON TECHNICAL INVESTIGATION OF ODOMETERS}




\section{THE NATIONAL BUREAU OF STANDARDS}

\section{Functions and Activities}

The functions of the National Burcau of Stanclards arc set forth in the Act of ('ongress, March 3, 1901, as amended by Congress in Public Law 619, 1950. Thiese include the develop)ment and maintenance of the national standards of measurement and the provision of means and mothouls for making measurenents consistent with these standards; the determination of pliysical constants and propertics of materials; the development of methods and instruments for testing nraterials, devices, and structures; advisory services to government agencies on scientific and technical problems; invention and development of devices to serve specinl needs of the Government; and the development of standard practices, codes, and specifications. 'The work includes basic and applied research, devclopment, enginecring, instrumcntatinu, l'stin!, eviluation, calibration services, and various consultation and information services. lipsalrh projects are also performed for other government ancencies when the work relates to and $41 p p l$ lements the basic program of the Burenu or when the Burcau's unique competenee is recpurenl. The scope of activities is suggested by the listing of divisions and sections on the illcikle of the back cover.

\section{Publications}

The results of the Bureau's research are published either in the Burcau's own serries of publications or in the journals of professional and scicntific societies. The Burcuu publishes three periodiculs available from the Govermment Printing Office: The Journal of Research, published in four scparate sections, presents complete scientific and technical papers; the 'Technical News Bulletin presents summary and preliminary reports on work in progress; and 1 he: Contral Radio Propagation Laboratory Ionospheric Predictions provides data for determininer the best frequencies to use for radio communications throughout the world. There are also five series of nonpcriodical publications: Monograplıs, Applied Mathematics Series, Handlınoks. Miscellaneous Publications, and Technical Notes.

A complete listing of the Bureau's publications can be found in National Bureau of Stanclurds Circular 460, Publications of the National Burcau of Standards, 1901 to June 1947 (\$1.2.5), and the Supplement to National Burcau of Standards Circular 460, July 1947 to June 19:5 (\$1.j0), and Misccllancous Publication 240, July 1957 to Junc 1960 (includes Titles of Paper's Published in Outside Journals 1950 to 1959) (\$2.25); available from the Supcrintendent of Documents, Government Printing Officc, Washington 25, D.C. 


\section{NATIONAL BUREAU OF STANDARDS Eechnical Note 195}

ISSUED AUGUST 6, 1963

\section{REPORT ON TECHNICAL \\ INVESTIGATION OF ODOMETERS}

Donald R. Mackay

NBS Technical Notes are designed to supplement the Bureau's regular publications program. They provide a means for making available scientific data that are of transient or limited interest. Technical Notes may be listed or referred to in the open literature. 
- 
1. Introduction $\ldots$

2. Instrument Calibration Course

3. Standard Test Instrument-_. 2

4. Instrument Calibration-_-n 2

5. Additional Testing Instruments- 4

6. Safety Precautions-_. 5

7. The Testing of Automobile Odometers Using the

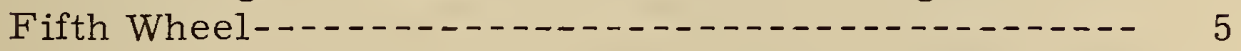

7. 1. Test Courses-

7.2. Test Vehicles--

7. 3. Test Procedures and Observations-------- 6

7. 4. Special Tests--_- 8

8. Test Results

8.1. Odometer Accuracy-n-.- 9

8.2. Effect of Variables-_... 10

8.3. Precision of Test--n 11

8.4. Test Conclusions

9. The Testing of Truck Odometers Using the

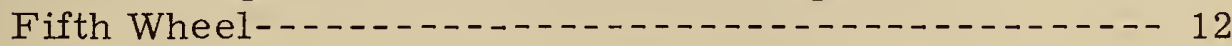

9. 1. Test Courses-1

9.2. Test Vehicles-_- 12

9.3. Test Procedures and Observations-_-_---- 12

9.4. Test Results-_..... 12

9.5. Effects of Variables-_-n

9. 6. Precision of Tests-_-n 13 
10. Road Tests-_._. 13

10.1. Test Procedures and Observations--_---- 13

10.2. Test Results-1-n 14

10.3. Test Conclusions-_-_- 15

11. Simulated-Road Tests-_-_-n 15

11. 1. Device Calibration--

11.2. Tests Conducted-_-_-_- 15

11.3. Test Procedures and Observations--------- 16

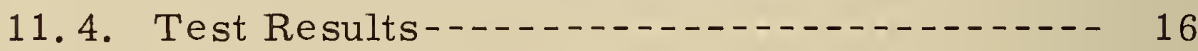

11.5. Test Conclusions-_-_- 17

12. Wheel Tests--

12.1. Test Procedures and Observations------- 18

12.2. Test Results--.-.- 18

12.3. Test Finding--_-n 19

12. 4. Test Conclusion-_-_-_-n 19

13. Conclusions-_-n 19

Appendix I. Summary of Automobile Odometer Accuracy

Tests (Using Fifth-Wheel Device)---.--- 21

Appendix II. Summary of Truck Odometer Accuracy.

Tests (Using Fifth-Wheel Device)-_-..-- 23

Appendix III. Proposed OWM Specifications for

"Fifth-Wheel" Testing Equipment-------- 24

Appendix IV. Proposed OWM Specifications for

Simulated-Road Testing Equipment------ 26 
Report on Technical Investigation of Odometers

\author{
Donald R. Mackay
}

A technical investigation of the accuracy of vehicle odometers was conducted by the Office of Weights and Measures. This report describes (1) the determination of the accuracy of odometers, (2) the identification of the factors that affect accuracy, and (3) the development of testing equipment and procedures to be used in the testing of odometers. Included in the investigation were fifthwheel tests, road tests, wheel tests, and simulatedroad tests. Each type of test is described, and the results discussed.

\title{
1. Introduction
}

At the request of the Committee on Specifications and Tolerances of the National Conference on Weights and Measures, the Office of Weights and Measures undertook a technical investigation of odometers on rental automobiles and trucks. The objectives of the study were (1) to determine the accuracy of odometers on rent vehicles under standard test conditions, (2) to identify the factors that affect accuracy under the test conditions, (3) to devise and prove testing equipment and procedures, and (4) to prepare recommendations to the committee appropriate amendments to existing technical requirements. This report will cover items (1), (2), and (3).

\section{Instrument Calibration Course}

In order to select and to calibrate from time to time a standard test instrument, a 1-mile calibration course was measured and marked on a new, unopened section of a freeway in Washington, D. C. This course, in the center of the outside lane on a fairly straight section of the freeway, was measured with a calibrated 100-foot steel tape held flat on the pavement under the prescribed 10-pound tension. A check 
measurement of the course differed from the original measurement by less than 1 part in 20,000 .

\section{Standard Test Instrument}

A commercially available device, known as a "fifth wheel," was selected as the standard test instrument (figure 1). This was a length-measuring instrument consisting of a carefully balanced rubbertired (pneumatic) wheel, approximately bicycle size, mounted through sealed, nearly friction-free ball bearings to a rigid frame. The frame was hinge-connected to an adjustable clamp which was used to attach the device to the rear bumper of an automobile. Between the frame and the bumper clamp were two over-center springs that held the unit, when it was not in use, in a vertical position above the bumper and that provided spring-loaded road contact when the wheel was in operating position. Specifications for such a testing device are found in Appendix III.

A fifth wheel may be equipped with either a mechanical or an electrical counter connected at the hub. The device used in this investigation was specially modified to accommodate a connector for a mechanical counter on one side and a connector for an electrical counter on the other side. The mechanical counter (figure 2) indicated digitally tens of miles, miles, tenths, and hundredths of miles and, with a small analog indicator, thousandths of miles. The electrical indicator, using as its 12 -volt power source either a cigarette-lighter connector or two 6-volt dry cells connected in series, indicated digitally miles, tenths, hundredths, and thousandths of a mile, with an easily discernible, visible, and audible signal, approximately 0.0005 mile. The electrical indicator was a high-speed electromagnetic counter fed by a make-and-break type impulse generator at the wheel.

The air pressure in the fifth-wheel tire was maintained at 25 psi (gage) $\pm 0.5 \mathrm{psi}$, as indicated on a calibrated, dial-type master tire-pressure gage.

\section{Instrument Calibration}

With the fifth wheel connected to an automobile, a number of twodirection runs (north and south) were made over the calibration course as follows: (1) The wheel was positioned so that the center of the hub was directly over the starting point, (2) the wheel was lifted from the pavement and rotated by hand until generator contact was just made, (3) the wheel was lowered carefully without additional rotation until 


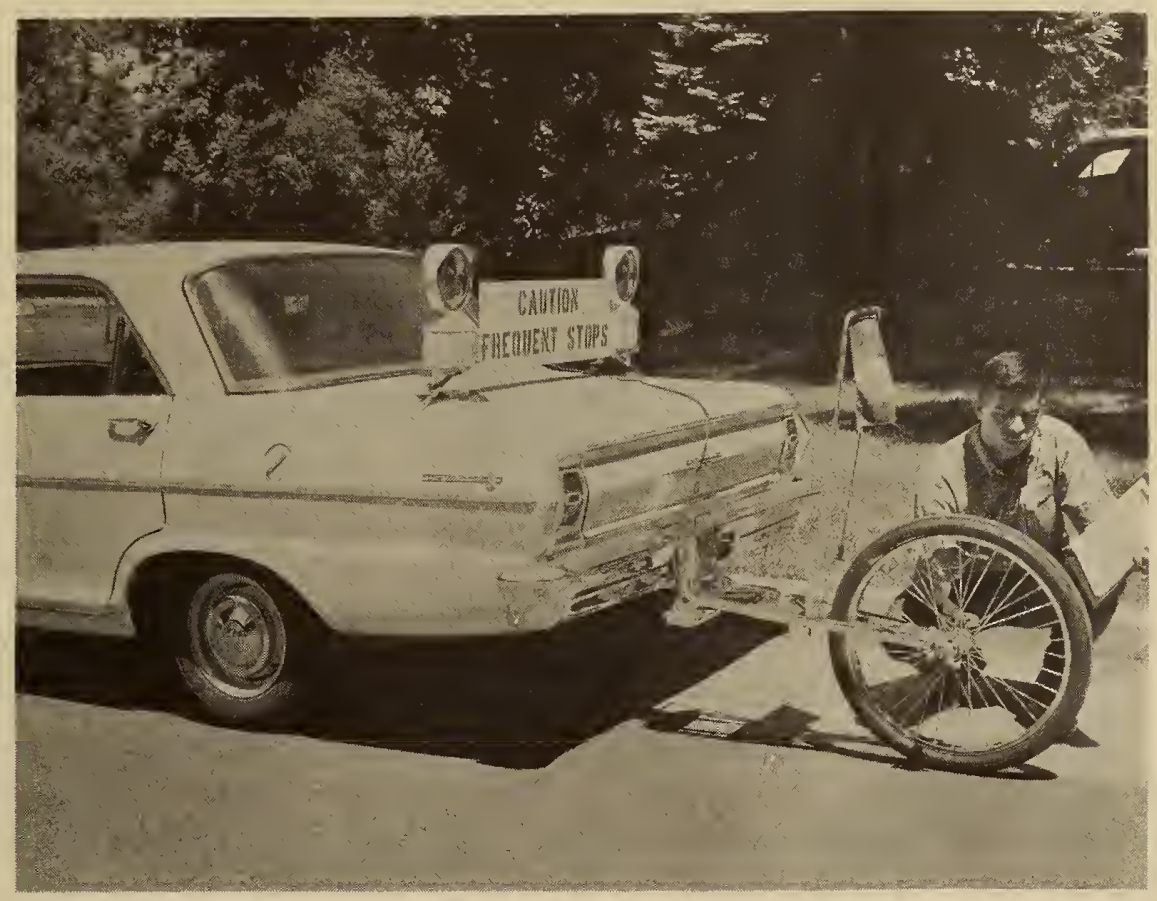

Figure 1. Fifth Wheel in Test Position

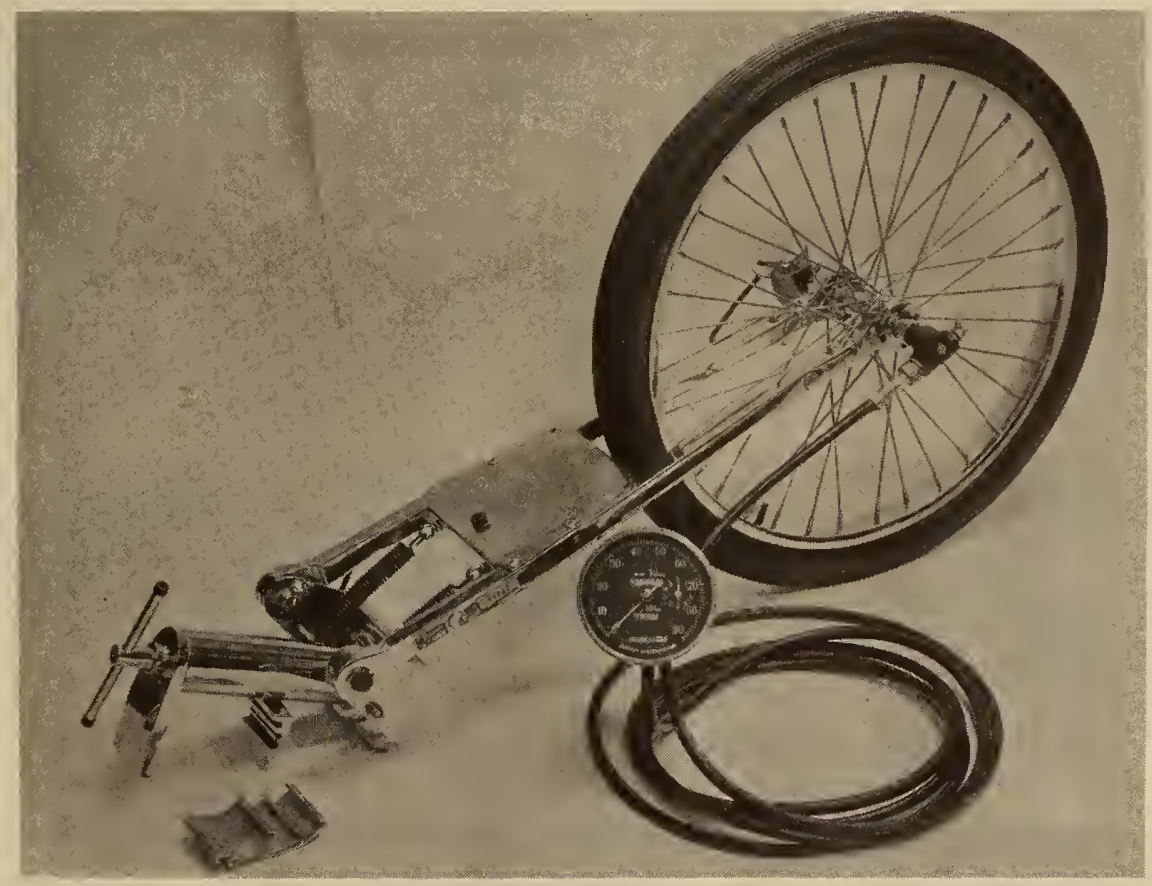

Figure 2. Fifth Wheel with Mechanical Counter 
pavement contact was reestablished, (4) the counter was zeroed, and (5) the calibration run was begun.

During a calibration run the vehicle driver maintained, as closely as practicable, the position on the roadway that would keep the fifth wheel directly over the measured course. Calibration runs were made at various speeds as indicated by the automobile speedometer. The results of the calibration runs were as follows:

$\begin{array}{ccc}\text { Indicated Speed } & \text { Fifth-Wheel Indication } & \text { Apparent Error } \\ 10 \mathrm{mph} & 1.005 \text { miles } & +0.005 \mathrm{mile} / \mathrm{mile} \\ 30 \mathrm{mph} & 1.004 \mathrm{miles} & +0.004 \mathrm{mile} / \mathrm{mile} \\ 50 \mathrm{mph} & 1.003 \mathrm{miles} & +0.003 \mathrm{mile} / \mathrm{mile}\end{array}$

In order to establish "standard" conditions for recalibration runs, a fifth-wheel "calibration" speed of 30 miles per hour indicated was empirically established. At $30 \mathrm{mph}$, original calibration runs provided, over the 1-mile measured course, a counter indication of 1.004 miles based on six successive runs with no variability between runs.

The fifth wheel was also recalibrated at various times during the testing program either to check the original data or to determine new calibration correction factors. A calibration determination made on June 1, 1962, reaffirmed the original data. However, another determination made on August 30 and 31, after almost 3000 miles of use, indicated a reading of 1.0045 for the measured mile. The tire wear during this three-month period of use had reduced the mean effective circumference of the fifth wheel, causing an additional indication of 0.0005 mile.

The calibration data provided the correction factors which could be applied to the fifth-wheel counter indications resulting from actual vehicle odometer tests. The corrected indication could then be used to obtain the absolute distance traveled and, thus, the absolute error of the odometer.

\section{Additional Testing Instruments}

Although the fifth wheel was the major piece of equipment used during the investigation, two small instruments were also used in determining test information concerning the vehicles--an air-pressure gage and a tire-tread depth gage. The air-pressure gage was used to 
measure the air pressure in the rear tires and to adjust the pressure to the level recommended by the automobile tire manufacturer. Four common tire-pressure gages were purchased, as well as a master tire-pressure gage. The four common gages were checked against the master gage for comparable accuracies. The gages were checked from 20.5 psi to 29.5 psi at approximately 0.5 psi intervals. The gage with the smallest average error ( 0.5 psi at 24 psi) was chosen for the tests. The individual errors of the other gages varied from 0 to $3.0 \mathrm{psi}$, or up to 10 percent of the master-gage reading.

Three ordinary tire-tread depth gages were procured and checked at various indications against a precision micrometer depth gage. Again, the gage with the smallest average error 10.002 inch between 4 and 12 thirty-seconds of an inch--the average tread depths normally encountered on automobile tires) was chosen for the tests.

\section{Safety Precautions}

The fifth wheel was modified by installing a red warning flag on a double-pole support, mounted on heavy-duty springs on the frame, between the wheel and the clamp. Two large amber-lens flashing lights were installed on a frame supported by suction cups and secured by adjustable straps and hold-down clips. A danger sign was also mounted on this frame which was placed on the rear trunk lid of each car tested to warn the drivers of automobiles approaching from the rear of the possibility of frequent stops in traffic lanes. (See figure 1.)

\section{The Testing of Automobile Odometers Using the Fifth Whee1}

\section{1. Test Courses}

The courses selected for the odometer-testing program included busy city streets (for slow speeds) and a highway (for high speeds). This provided an opportunity to evaluate the accuracy of the odometers under both types of driving conditions. The city course involved four right and three left turns, numerous stop signs and traffic lights, single-lane and dual-lane traffic conditions, and a maximum speed limit of $35 \mathrm{mph}$. The highway course was over a section of an interstate highway having a posted speed limit of $60 \mathrm{mph}$.

Originally, the test runs were 5 miles each and were made in the following order: city-northbound, highway-northbound, (turn- 
around), highway-southbound, city-southbound. This sequence provided duplicate data for the city and the highway runs. After twelve cars were tested using the 5-mile test runs, special tests were conducted to determine if a shorter test run would provide equally reliable information. These tests involved cars of two different makes and at least three replicates for each car over course lengths of 1 mile, 2 miles, and 5 miles. Comparative analysis of the data indicated that two 2 -mile runs would actually provide better information than a single 5-mile run, since the total test variability in each 2 -mile run was not significantly different from that in each 5-mile run. However, the total test error in a one-mile run was sufficiently large (approximately 0.6 percent) to rule out the use of this course length.

The test runs were then made in the following order: two successive 2-mile city-northbound runs, two 2-mile highwaynorthbound runs, (turn around), two 2-mile highway-southbound runs, and two 2-mile city-southbound runs. This course then provided four city runs and four highway runs, each 2 miles in length. The replicates made possible the elimination of any single runs which yielded obviously faulty data, without significantly reducing the reliability of the remaining data.

\subsection{Test Vehicles}

The vehicles used in the odometer tests were provided by Washington, D. C., car-rental agencies through arrangements made by the District Department of Licenses and Inspections. They were selected at random from the fleet of cars available on any particular day. The cars tested were predominently popular size cars and compacts. Of the 48 cars tested, 32 fell into these two groups, 16 in each group. Four large, high-priced cars, 4 American sports cars, and 5 other luxury-type cars were tested. Also included in the test group were 3 station wagons. All vehicles tested were of domestic manufacture.

\subsection{Test Procedures and Observations}

The vehicles to be tested were picked up at the car-rental agency in the midtown area and driven to the grounds of the National Bureau of Standards. Here, the fifth wheel was attached to the rear bumper, the counter connected and secured, and the warning sign and light bar attached to the rear trunk lid. The "Odometer Test Report" data sheet (see figure 3) was filled in with such pre-test information as vehicle, owner, number, make, model, mileage, and license number, and also with data on the rear tires, including the manu- 
Date: July II, 1962

Vehicle

Owner:

Make:

Drive: $A_{\text {Lith: }}$

Mileage: 5254

Rear Tires

Manuf.:

Diameter:

Pressure: L 28 R 24 RIP 24

Course

No: $\frac{2}{\text { Notes: }}$

No: $\frac{2}{\text { Notes: }}$
Vehicle No.: 6259

Model:

Type: 4 -tor

Motor: $V-9$ Serial No. 4197531246

License No.: KD 632

Type:

Size: $7: 56 \times 14$

Diameter:

Tread Depth: L 9.6 R9.4 ND

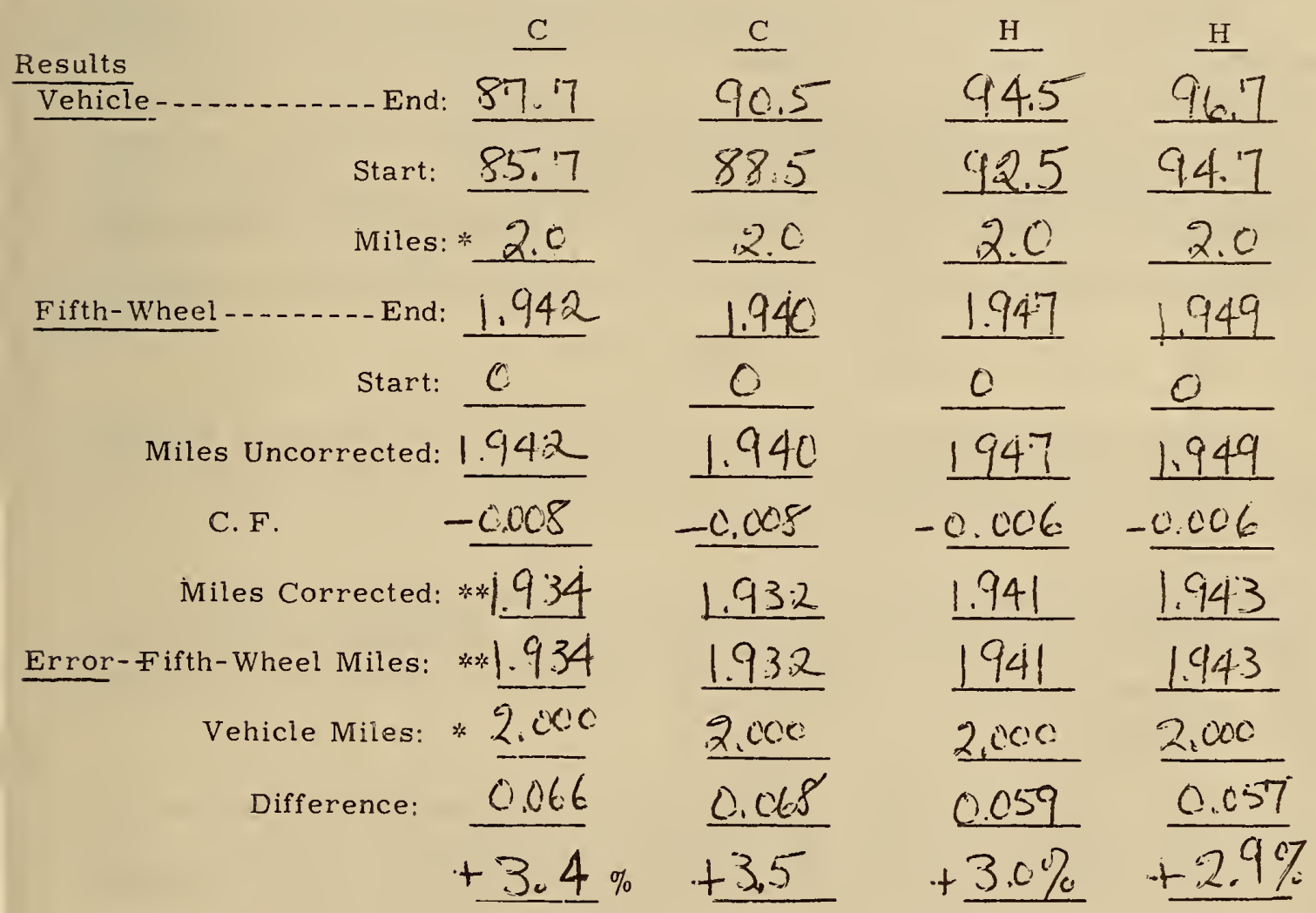

Figure 3. Odometer Test Report

7 
facturer, type, and size of the tires. The tread depth, measured at 4 points along a profile cross section of the tread, and the air pressure in each tire were then measured and recorded. Following this, the air pressure in each rear tire was adjusted to the pressure recommended by the tire manufacturer.

In preparation for the start of the test, the vehicle was driven slowly until either the 5 or 7 tenth-mile figure reached a point in its travel where the straight top edge of the number was just reaching the bottom edge of the odometer window frame. (Assuming a fixed position of the driver's line of sight, this position of the odometer tenthmile indication could be repeated very accurately at the end of the test run.) At this precise position of the odometer indication, the vehicle was stopped, the fifth wheel was placed in operating position, the counter energized and zeroed, and the first test begun. As the end of the first test run was approached, the vehicle was slowed down and then brought to a stop when the driver had duplicated, to the best of his ability, the original position of the tenth-mile indication. The counter indication was observed and recorded and the counter reset before the second test run was started.

At the end of the second northbound highway test, the technician checked the rear tire air pressures since the high speed driving usually caused a pressure buildup. If necessary, the tire pressure was again adjusted to the recommended pressure since the accumulation of comparative data was based on standard test conditions. The southbound test-course procedures were the same as the northbound procedures.

\subsection{Special Tests}

Special tests were conducted to determine the effects of certain variables on odometer accuracy--wet pavements, vehicle speed, vehicle load, and vehicle tire pressure.

Wet Pavements--Whenever a test in progress had to be stopped because of rain showers, a new test was started on the wet roadway and, later, the same car was retested to provide complete information for dry pavements.

Vehicle Speed--Special tests were conducted over the highway course to determine the effect of vehicle speed on odometer accuracy. Two separate makes of medium-priced cars were selected for these tests. Two-mile runs were made at speeds of $30 \mathrm{mph}$ and $60 \mathrm{mph}$. 
Vehicle Load--The same two cars used in the special speed tests were used in the load tests. Each vehicle was tested over the regular test course with the driver only, and again with the driver plus 400 pounds of 50 -pound weights, 100 pounds in the front seat and 300 in the rear seat.

Vehicle Tire Pressure--Special tests were conducted to determine the effect of pressures in excess of those recommended by the tire manufacturer on the accuracy of the odometer indication. Comparative tests were made at $24 \mathrm{psi}$ and 30 psi over the normal test course.

\section{Test Results}

\section{1. Odometer Accuracy}

The average error for all cars driven under city and highway conditions was +3.21 percent. The average error for all city runs was +3.50 percent, with a range of from +0.10 percent to +7.25 percent. The average error for all highway runs was +2.92 percent, with a range of from -0.50 to +6.90 percent. Table 1 shows the average errors for the types and makes of automobiles tested under both city and highway driving conditions.

Table 1. Average Automobile Odometer Errors (Percent of Overregistration)

\begin{tabular}{|c|c|c|c|c|c|}
\hline $\begin{array}{l}\text { Vehicle } \\
\text { Type }\end{array}$ & $\begin{array}{c}\text { Vehicle } \\
\text { Manufacturer }\end{array}$ & $\begin{array}{l}\text { Number } \\
\text { Vehicles }\end{array}$ & $\begin{array}{l}\text { City } \\
\text { Error }\end{array}$ & $\begin{array}{c}\text { Highway } \\
\text { Error }\end{array}$ & $\begin{array}{c}\text { Average } \\
\text { Error }\end{array}$ \\
\hline Popular & Average & $\begin{array}{c}8 \\
\frac{8}{(16)}\end{array}$ & $\begin{array}{l}4.47 \\
3.00 \\
3.73\end{array}$ & $\begin{array}{l}3.98 \\
2.50 \\
3.24\end{array}$ & $\begin{array}{l}4.23 \\
2.75 \\
3.49\end{array}$ \\
\hline Compact & $\begin{array}{c}1 \\
2 \\
3 \\
\stackrel{4}{\frac{4}{r a g e}}\end{array}$ & $\begin{array}{c}4 \\
4 \\
4 \\
\frac{4}{(16)}\end{array}$ & $\begin{array}{l}5.42 \\
3.85 \\
0.46 \\
3.11 \\
3.21\end{array}$ & $\begin{array}{l}4.88 \\
3.18 \\
0.08 \\
2.62 \\
2.69\end{array}$ & $\begin{array}{l}5.15 \\
3.51 \\
0.28 \\
2.87 \\
2.95\end{array}$ \\
\hline Luxury & $\begin{array}{c}1 \\
2 \\
3 \\
\text { Average }\end{array}$ & $\begin{array}{r}3 \\
3 \\
\left(\frac{7}{13}\right)\end{array}$ & $\begin{array}{l}4.28 \\
3.10 \\
3.29 \\
3.47\end{array}$ & $\begin{array}{l}3.63 \\
2.28 \\
2.54 \\
2.73\end{array}$ & $\begin{array}{l}3.96 \\
2.69 \\
2.91 \\
3.10\end{array}$ \\
\hline Wagon & 1 & (3) & 3.95 & 3.27 & 3.61 \\
\hline Averages & & (48) & 3.50 & 2.92 & 3.21 \\
\hline
\end{tabular}


The average difference (which was fairly consistent for all tests) between the city test and the highway test was 0.6 percent. The odometer indicated more for the city run, providing greater overregistration errors. The test results for all cars are found in Appendix I, grouped by types of cars and by manufacturers.

\subsection{Effect of Variables}

The specific results of the tests conducted to determine the effect of these variables on odometer accuracy are not important in themselves and are not presented since they apply only to the individual cars used in these specific tests. The differences in results of tests conducted under different conditions are important as they indicate the relative changes in the odometer errors as caused by the changes in the testing conditions.

Wet Pavements--Only a limited number of tests were conducted to determine the effect of wet pavements on the odometer accuracy. These data, however, provided indications that the slippage of the rear wheels on the wet pavement caused larger positive errors than the drypavement tests. The errors obtained in the wet pavement tests were up to one and one-half times as great as those obtained in the dry pavement tests.

Vehicle Speed--A number of highway tests were conducted to determine the effect of speed on odometer accuracy. These test data indicated that as the vehicle speed was increased from $30 \mathrm{mph}$ to $60 \mathrm{mph}$ the odometer reading was decreased, on the average, by a factor of 0.55 percent of the distance traveled. The increase in vehicle speed caused an increase in the rolling radius of the tire, which in turn reduced the odometer indication.

Vehicle Load--The tests conducted with an additional load of 400 pounds in the vehicle provided an increase in the odometer reading, on the average, of 0.46 percent of the distance traveled. The increase in load caused a decrease in the rolling radius of the tire, which in turn caused an overregistration effect in the odometer indication.

Vehicle Tire Pressure--The tests conducted to determine the effect of inflating the tires to $30 \mathrm{psi}$, or $6 \mathrm{psi}$ above the recommended pressure provided a decrease in the odometer reading of 0.75 percent of the distance traveled. 


\subsection{Precision of Test}

The uncertainty of the indicated odometer error that could be attributed to the variability of the fifth-wheel tests was not more than \pm 0.27 percent. ${ }^{*}$ This test error was well within the 1 percent error limit which is recommended in NBS Handbook 44, entitled "Specifications, Tolerances, and Regulations for Commercial Weighing and Measuring Devices." This limit is arrived at considering the maximum error in the recommended testing equipment of 25 percent of the tolerance to be applied.

\subsection{Test Conclusions}

The results of these tests clearly indicate that through the use of the fifth-wheel device, odometer errors can be determined by a single run with a total uncertainty of less than one percent, allowing 0.54 percent for the possible effect of random variations and the remaining part of the allowance for possible systematic errors.

The results also indicated that the average odometer provided an overregistration error of more than 3 percent under standard test conditions. It was found that wet pavements and additional vehicle loads tended to increase the odometer error, while increased vehicle speed and increased tire pressures tended to decrease the odometer error.

*Successive runs did not yield identical results, as is illustrated by the example given in figure 3. This variability is mainly due to reading errors, but may also include the effects of such factors as speed, temperature, and driver habits. A statistical analysis of the variability led to a standard deviation of 0.00359 mile for a single 2 -mile run (based on tests of popular cars involving 73 degrees of freedom). Using three standard deviations as a limit of the effect of random variation on the results, leads to an uncertainty value of \pm 0.27 percent for the average of four runs. This value is related to the precision of the measurement procedure and does not include any allowance for systematic differences in the test procedure that would be introduced if, for example, a tire pressure other than that specified in the test were used. 


\section{The Testing of Truck Odometers Using the Fifth Wheel}

\subsection{Test Courses}

The test course for the trucks tested was essentially the same as the 2-mile city and highway courses described for the automobiles. Three trucks did not have tenth-mile odometer indications and were driven over either at least two 5-mile courses or one 10-mile course.

\subsection{Test Vehicles}

Ten of the trucks tested were obtained from two of the national rental agencies in Washington, D. C. The other three trucks were borrowed from the National Bureau of Standards motor pool. Six of the trucks were panel trucks; four were rated at $1 / 2$ ton, one at $3 / 4$ ton, and one at 1 ton. Three of the trucks were pickups; one of these was rated at $1 / 2$ ton, and two at $3 / 4$ ton. Two of the trucks were stepvans and two were 14-foot vans. Two trucks, a step-van and a pickup, had snow tires on the rear wheels, but were tested to obtain data.

\subsection{Test Procedures and Observations}

The procedures followed and observations made during the testing of truck odometers were essentially the same as those of the automobile tests. The only differences occurred in the placing of the fifth wheel in operating position prior to obtaining a precise odometer indication at the start of the test. This was done to eliminate the need for leaving the truck on the busy streets.

\subsection{Test Results}

The average error for all trucks driven under both city and highway conditions was -0.4 percent. The average error for all city runs was -0.25 percent with a range of from +5.2 percent to -5.2 percent. The average error of all highway runs was -0.55 percent with a range of from +5.2 percent to -5.0 percent. The average error for the eleven trucks with regular tires (eliminating from the average the two trucks with snow tires) was +0.8 percent. The average error for the city runs was +1.2 percent and the average error for the highway runs was +0.6 percent for these eleven trucks. The results of all trucks tested are found in Appendix II. 
One truck, a $3 / 4$ ton pickup, was selected to determine the effect of the various variables on the resulting odometer accuracy. This truck had an average odometer error of +0.8 percent for the normal city runs. Highway speeds of up to $50 \mathrm{mph}$ did not significantly influence this error under any conditions. However, an increase in tire pressure from $30 \mathrm{psi}$ (recommended) to $60 \mathrm{psi}$ caused a decrease in the odometer reading of 0.9 percent of the distance traveled. An increase in load of 1550 pounds per rear tire (at 30 psi) caused an increase in the odometer reading of 1.4 percent of the distance traveled. The effects of these variables caused changes in the rolling radius of the tires, which in turn caused the change in odometer accuracy.

\subsection{Precision of Tests}

The limits of variability of the test results, were found to be \pm 0.35 percent for trucks as compared to the \pm 0.27 percent found in the automobile test. This increased variability is mainly attributable to the difficulty in precisely duplicating the odometer indications used in the test. The difficulty in reading truck odometers was caused by the parallax effects created by the greater distances between the instrument panels and the odometer figures in trucks as compared to those found in automobiles.

\section{Road Tests}

Tests were conducted over measured courses one mile and two miles in length with three different automobiles to determine the effectiveness of the road test in determining odometer accuracy. The measured courses were laid out with the fifth wheel on fairly straight and level concrete highways. The beginning and end of each course was prominently marked. Courses were laid out along both the northbound and the southbound lanes so that data could be obtained while traveling in both directions.

\subsection{Test Procedures and Observations}

The pre-test procedures and observations utilized in the fifthwheel tests were also followed in the road tests. Following this, the vehicle to be tested was driven to the starting point and accurately positioned by lining up a point in the right window with two points placed in a line perpendicular to the roadway at the starting point. The front wheels of the vehicle were then blocked with chocks, and the rear 
wheels were raised from the roadway surface by jacking up the rear end. The technician then started the motor and allowed the odometer to advance until the tenth-mile digit reached a test starting point.

After accurately positioning the tenth-mile digit, the jack was released and the chocks removed. The technician then drove the vehicle over the course until either the 1.0- or 2.0-mile indication was obtained. At this point the vehicle was stopped, and a mark was made on the pavement even with the point in the front right window which was previously used, to determine the position of the vehicle at the starting point.

The distance from this point to the end of the course was then measured with a calibrated 100 -foot steel tape. This distance, representing the error of the odometer was used in determining the variations resulting from the use of this type of test. The fifth wheel was used in these tests as the standard mileage-measuring instrument and data obtained through the use of the wheel was also recorded.

\subsection{Test Results}

The results obtained using the Road Test in determining odometer errors are shown in Table 2. The maximum difference observed between the fifth-wheel test and the road test for a one-mile course was 5.0 feet, the average difference was only 1.6 feet. The results for the two-mile course indicated a maximum difference of 10.0 feet with an average difference of only 4.2 feet.

Table 2. Odometer Errors Observed in Road Tests (Averages of Four Test Runs)

\begin{tabular}{c|c|c|c|c|c}
\hline Car & Course & $\begin{array}{c}\text { Average } \\
\text { th-Wheel } \\
\text { Error }\end{array}$ & $\begin{array}{c}\text { Average } \\
\text { Measured } \\
\text { Error }\end{array}$ & $\begin{array}{c}\text { Range of } \\
\text { Differences }\end{array}$ & $\begin{array}{c}\text { Average } \\
\text { Difference }\end{array}$ \\
\hline \multirow{2}{*}{ A } & (miles) & $\begin{array}{c}\text { (feet) } \\
117.5\end{array}$ & $\begin{array}{c}\text { (feet) } \\
115.4\end{array}$ & -1.3 to +5.1 & -2.1 \\
& 2 & 229.7 & 236.3 & -10.0 to -4.2 & +6.6 \\
B & 1 & 260.0 & 260.2 & -1.2 to +2.1 & +0.2 \\
& 2 & 493.7 & 491.2 & -6.0 to +1.0 & +2.5 \\
C & 1 & 264.0 & 263.8 & -1.2 to +0.7 & -0.2 \\
& 2 & 554.4 & 556.7 & +1.9 to +2.6 & +2.3 \\
\hline
\end{tabular}


These results proved that an accurately measured course of either one or two miles can provide very satisfactory evaluations of odometer accuracies if precision and exacting procedures are employed during the testing operations.

The one-mile test courses provided an average difference of 1. 6 feet between the fifth-wheel tests and the road tests. Two-mile test courses provided an average difference of 4.2 feet between the two types of test.

\section{Simulated-Road Tests}

Simulated-road tests were conducted using a commercial device made specifically for odometer testing. This device consisted of two pairs of accurately machined rollers, approximately 8 inches in diameter, supported by heavy-duty bearings, mounted in a steel frame. An electrical contactor was connected through a gear reduction unit to one of the rear cylinders under the rear wheel of the vehicle being tested. A ramp was provided to allow the vehicle to be positioned on the rollers. A high-speed electrical counter was provided which indicated distance traveled in tens, units, tenths, hundredths, and thousandths of miles. The power required to actuate the circuit was provided through a common 115-volt a.c. outlet. Specifications for this type of odometer testing equipment are found in Appendix IV.

\section{1. Device Calibration}

The simulated-road testing device was calibrated by computing the distance traveled by the cylinder in an indicated mile and determining the correction factor. The distance traveled per indicated mile was computed by determining the measured circumference of the cylinder and multiplying it by the exact number of revolutions in an indicated mile. The distance traveled by the surface of the cylinder was 5293 feet for each 1.000 mile indicated by the simulated-road testing device counter. Thus, one mile would be equal to an indication of 0.997 , or a correction factor of -0.003 mile would have to be applied to each mileage indication provided by the simulated-road testing device.

\subsection{Tests Conducted}

The simulated-road testing equipment was used to evaluate the accuracy of a vehicle odometer under a number of conditions to deter- 
mine their relative effects on the resulting accuracy. These conditions were as follows:

1. Car inclined and car level.

2. $25 \mathrm{mph}$ and $50 \mathrm{mph}$.

3. Driver only and driver plus 400-pound load.

4. 24 psi tire pressure and 30 psi tire pressure.

5. Reading precision--operator differences.

A test distance of two miles was selected, on the basis of the determination made in the fifth-wheel tests for the optimum length of test.

Only one car was involved in these tests, as this was considered sufficient, from a study of the method, to determine the effectiveness of the simulated-road tests in duplicating the results of the actual road tests.

\subsection{Test Procedures and Observations}

After completion of the previously established pre-test procedures and observations, the vehicle under test was positioned with the rear wheels on the cylinders of the testing device. The tire pressure was checked and adjusted if necessary, and then the rear wheels advanced under power until the odometer indication reached a starting point. At this time the counter circuit was energized and the indicator was zeroed. Two indicated odometer miles were then traveled, the vehicle wheels stopped exactly at the same tenth mile indication that was used in starting the test. The counter indication at this point was then read and recorded.

\subsection{Test Results}

The average error of the odometer on the vehicle tested in level position under the standard conditions of $25 \mathrm{mph}, 24$ psi tire pressure, and with the driver only in the car was 0.075 mile in two miles or an overregistration error of 3.75 percent. The range encountered in the twenty runs was from 3.50 percent to 3.95 percent.

The results of the tests conducted to determine the effect of the position of the car (level versus inclined) on the simulated-road testing device indicated an average difference of 0.002 mile in the twomile run or 0.1 percent. The tests conducted with car level yielded higher counter reading than those conducted with the car inclined, thus the inclined position caused a greater overregistration of the vehicle odometer than the level position. The difference, however, in the 
results obtained from the two positions was not statistically significant. Thus, it was reasoned that tests could be conducted with cars positioned on the incline resulting from backing the rear wheels of the vehicle up on the unit; the unit being located on the road surface, and the front wheels of the vehicle under test remaining at road surface level.

The results of the tests conducted to determine the effect of speed on odometer accuracy indicated that at $25 \mathrm{mph}$ the vehicle odometer had a 0.6 percent greater overregistration than at $50 \mathrm{mph}$.

The results of the tests conducted to determine the effect of an additional 400-pound load on the odometer error indicated that this additional load reduced the rolling radius sufficiently to cause an overregistration error 0.7 percent greater than the errors incurred in the tests conducted with the driver only.

The simulated-road tests conducted to evaluate the effect of an increased tire pressure, 6 psi above the normal 24 psi, showed that the increased rolling radius of the overinflated tire provided a smaller overregistration error than the error provided by the normally inflated tires.

The tests conducted to determine reading precision of various people indicated that odometer indication could be repeated to within 0.001 mile by an experienced operator. Differences of up to 0.005 mile were obtained by inexperienced people who participated in these particular tests.

\subsection{Test Conclusions}

The tests involving the simulated-road testing equipment proved that this equipment, when used in conjunction with the specific test procedures developed for this testing and conducted by experienced personnel, could very accurately and effectively provide an evaluation of vehicle odometer accuracy. The accuracy of the simulated-road tests was not significantly different from that of the fifth-wheel tests. The results of tests conducted to determine the effects of the variables were very similar to the results obtained in the fifth-wheel road tests.

\section{Wheel Tests}

Wheel tests were conducted in an effort to evaluate the effectiveness of this type of test in determining the accuracy of a vehicle 
odometer. The vehicle that was used in these tests, obtained from the GSA motor pool, was a popular-sized 4-door sedan.

\section{1. Test Procedures and Observations}

The vehicle was positioned on straight and level section of roadway, and a chalk mark was placed on the side wall of the tire, perpendicular to the pavement, and another mark was placed on the pavement, perpendicular to the tire, as the starting line. The car was then slowly driven on a straight path until the wheel had made exactly ten revolutions, as determined by an observer walking along beside the car. At the point where the line on the tire was again exactly perpendicular to the roadway, a chalk mark was made on the pavement. The distance between this point and the starting point was measured with a calibrated 100-foot steel tape. This distance was used to calculate the distance traveled per wheel revolution, or the effective tire circumference. This procedure was repeated three times.

The vehicle was then positioned on a level section of pavement, the front wheels were blocked with chocks, and the right rear wheel was jacked up. A revolution counter, held by a clamp on a laboratory stand, was then attached by means of a suction cup. The technician started the motor and allowed the tenth-mile digit of the odometer to reach a starting point. After setting the counter at zero, the odometer was allowed to advance exactly one mile, and the number of wheel revolutions was noted. This entire procedure was repeated three times.

\subsection{Test Results}

The results of the three determinations of the distance traveled per wheel revolution were as follows:

(a) $67 \mathrm{ft} 10 \mathrm{in}$. or 6.783 feet per revolution.

(b) $68 \mathrm{ft} 4 \mathrm{in}$. or 6.833 feet per revolution.

(c) $68 \mathrm{ft} 2$ in. or 6.817 feet per revolution.

The results of the determination of revolutions per indicated odometer mile were as follows:

(a) 751.8 revolutions per mile.

(b) 749.4 revolutions per mile.

(c) 753.0 revolutions per mile. 
If the average of the three determinations of feet per revolution were used in computing the distance traveled for each of the three odometer miles, a maximum difference of 24.6 feet or 0.47 percent would result. If the extremes of each of the determinations were used in computing the distance traveled, a maximum difference of 62 feet or 1.17 percent would result. These figures indicate that the wheel test is not an accurate method of evaluating odometer accuracy, since the errors involved exceed the 1.0 percent limit normally imposed in odometer testing programs.

\subsection{Test Finding}

A second and third car were also selected for the wheel test, but it was found that, due to a new device in the rear end which prevents differential slip, it was impossible to advance only one wheel at a time. When both wheels were jacked up, one wheel rotated forward while the other rotated backward, reducing the total forward revolutions per wheel.

\section{4. Test Conclusion}

The results of the one possible test, as well as the findings in two additional tests, indicated that the wheel test could not effectively be used to determine the accuracy of vehicle odometers, since differences in excess of 1.0 percent could result from variations of the number of revolutions per mile.

\section{Conclusions}

The test results indicated the average automobile odometer tested provided an overregistration error slightly greater than 3 percent under standard test conditions. It was found that wet pavements and additional vehicle loads tended to increase the overregistration error, while increased vehicle speeds and tire pressures tended to decrease the overregistration error.

The results of the limited number of tests conducted to determine the error of truck odometers provided an average error of +0.8 percent. It was found that vehicle speed had little effect on the resulting error although tire pressure and vehicle load did significantly effect the odometer error.

It was found that vehicle odometer accuracy can be evaluated quite precisely by a number of methods. The fifth-wheel device, the 
simulated-road testing device, and the measured road course were successfully used in this investigation of odometer accuracy. The wheel test was found to be inadequate for odometer testing.

The fifth-wheel tests and the simulated-road tests were found to have the highest degree of repeatability and precision. The road test, because of the dependence upon the driver to duplicate exactly the test course with each car tested, had slightly lower precision than the other two methods. However, any testing program involves the use of specific test procedures, precise determinations, carefully maintained equipment, and accurate interpretation of data.

The author wishes to acknowledge the assistance received from (1) J. M. Cameron, Division 11.03, for the statistical analysis and interpretation of the data; (2) H. F. Wollin, Division 17.0, for conducting the simulated-road tests; (3) J. H. Griffith, Division 17.0, for conducting the other tests; and (4) M. W. Jensen, Division 17.0, for his guidance and contributions. 
Appendix I

Summary of Automobile Odometer Accuracy Tests

(Using Fifth-Wheel Device)

\begin{tabular}{|c|c|c|c|c|}
\hline $\begin{array}{c}\text { Test } \\
\text { Number } \\
\end{array}$ & $\begin{array}{c}\text { Type } \\
\text { Vehicle } \\
\end{array}$ & $\begin{array}{c}\text { City } \\
\text { Error--\% } \\
\end{array}$ & $\begin{array}{c}\text { Highway } \\
\text { Error--\% } \\
\end{array}$ & $\begin{array}{c}\text { Average } \\
\text { Error--\% } \\
\end{array}$ \\
\hline 1 & $P-1$ & 2.60 & 2.22 & 2.41 \\
\hline 2 & $P-1$ & 3.36 & 2.84 & 3.10 \\
\hline 3 & $P-1$ & 2. 98 & 2.24 & 2.61 \\
\hline 4 & $\mathrm{P}-1$ & 5.32 & 4. 36 & 4.84 \\
\hline 5 & $\mathrm{P}-1$ & 6.24 & 5.72 & 5.98 \\
\hline 6 & $\mathrm{P}-1$ & 5.18 & 4. 74 & 4.96 \\
\hline 7 & $P-1$ & 6.52 & 6.24 & 6.38 \\
\hline 8 & $P-1$ & 3.55 & 3.52 & 3.54 \\
\hline 9 & $\mathrm{P}-2$ & 3.16 & 2.54 & 2.85 \\
\hline 10 & $P-2$ & 3.20 & 2.66 & 2.93 \\
\hline 11 & $\mathrm{P}-2$ & 3.48 & 2.90 & 3.19 \\
\hline 12 & $P-2$ & 2.68 & 2.14 & 2.41 \\
\hline 13 & $\mathrm{P}-2$ & 3.54 & 2. 98 & 3.26 \\
\hline 14 & $\mathrm{P}-2$ & 4.16 & 3.68 & 3.92 \\
\hline 15 & $\mathrm{P}-2$ & 0.48 & -0.10 & 0.19 \\
\hline 16 & $\mathrm{P}-2$ & 3.30 & 3.16 & 3.23 \\
\hline 17 & $\mathrm{C}-1$ & 5.30 & 4.95 & 5.12 \\
\hline 18 & $C-1$ & 7.25 & 6.90 & 7.08 \\
\hline 19 & $C-1$ & 5.00 & 4.20 & 4.60 \\
\hline 20 & $C-1$ & 4.15 & 3.45 & 3.80 \\
\hline 21 & $\mathrm{C}-2$ & 4.05 & 3.60 & 3.82 \\
\hline 22 & $C-2$ & 3.50 & 2.55 & 3.02 \\
\hline 23 & $\mathrm{C}-2$ & 4.15 & 3.55 & 3.85 \\
\hline 24 & $C-2$ & 3.70 & 3.00 & 3.35 \\
\hline 25 & $\mathrm{C}-3$ & 0.30 & 0.01 & 0.15 \\
\hline 26 & $\mathrm{C}-3$ & 0.70 & 0.30 & 0.50 \\
\hline 27 & $C-3$ & 0.75 & 0.50 & 0.62 \\
\hline 28 & $C-3$ & 0.10 & -0.50 & -0.20 \\
\hline
\end{tabular}


Appendix I (Continued)

Summary of Automobile Odometer Accuracy Tests

(Using Fifth-Wheel Device)

\begin{tabular}{|c|c|c|c|c|}
\hline $\begin{array}{c}\text { Test } \\
\text { Number }\end{array}$ & $\begin{array}{c}\text { Type } \\
\text { Vehicle } \\
\end{array}$ & $\begin{array}{c}\text { City } \\
\text { Error- } \% \\
\end{array}$ & $\begin{array}{l}\text { Highway } \\
\text { Error--\% }\end{array}$ & $\begin{array}{c}\text { Average } \\
\text { Error }--\%\end{array}$ \\
\hline 29 & $C-4$ & 3.25 & 2.60 & 2.92 \\
\hline 30 & $C-4$ & 1.00 & 0.50 & 0.75 \\
\hline 31 & $C-4$ & 5.25 & 4.75 & 5.00 \\
\hline 32 & $C-4$ & 2.95 & 2.65 & 2.80 \\
\hline 33 & L-1 & 2.35 & 1.70 & 2.02 \\
\hline 34 & $L-1$ & 5.00 & 4.30 & 4.65 \\
\hline 35 & $\mathrm{~L}-1$ & 5.50 & 4. 90 & 5.20 \\
\hline 36 & $\mathrm{~L}-2$ & 3.00 & 2.20 & 2.60 \\
\hline 37 & $\mathrm{~L}-2$ & 3.10 & 2.30 & 2.70 \\
\hline 38 & $L-2$ & 3.20 & 2.35 & 2.78 \\
\hline 39 & $L-3$ & 2.40 & 1.50 & 1.95 \\
\hline 40 & $\mathrm{~L}-3$ & 2.95 & 2.15 & 2.55 \\
\hline 41 & $L-3$ & 3.15 & 2.55 & 2.85 \\
\hline 42 & $L-3$ & 3.75 & 3.25 & 3.50 \\
\hline 43 & $L-3$ & 2.55 & 1.35 & 1. 95 \\
\hline 44 & $\mathrm{~L}-3$ & 1.70 & 0.75 & 1.22 \\
\hline 45 & $L-3$ & 6.50 & 6.20 & 6.35 \\
\hline 46 & $W-1$ & 4.30 & 4.00 & 4. 15 \\
\hline 47 & $W-1$ & 2.15 & 1.20 & 1. 68 \\
\hline 48 & W - 1 & 5.40 & 4. 60 & 5.00 \\
\hline Average & & 3.50 & 2.92 & 3.21 \\
\hline
\end{tabular}

Key to Type of Vehicles

$P=$ Popular Size Cars

$\mathrm{L}=$ Luxury and Sport Cars

$\mathrm{C}=$ Compact Cars

$\mathrm{W}=$ Station Wagons

Numbers differentiate car manufacturers. 
Appendix II

Summary of Truck Odometer Accuracy Tests

(Using Fifth-Wheel Device)

\begin{tabular}{|c|c|c|c|c|}
\hline $\begin{array}{c}\text { Test } \\
\text { Number }\end{array}$ & $\begin{array}{c}\text { Type } \\
\text { Vehicle }\end{array}$ & $\begin{array}{c}\text { City } \\
\text { Error--\% }\end{array}$ & $\begin{array}{l}\text { Highway } \\
\text { Error--\% }\end{array}$ & $\begin{array}{c}\text { Average } \\
\text { Error--\% }\end{array}$ \\
\hline 1 & $\mathrm{P}-1$ & -4.3 & -4.3 & -4.3 \\
\hline 2 & $P-1$ & -0.8 & -0.9 & -0.8 \\
\hline 3 & $P-1$ & 0.1 & 0 & 0 \\
\hline 4 & $P-1$ & 1.1 & 1.0 & 1.0 \\
\hline 5 & $\mathrm{P}-2$ & 0.4 & 0 & 0.2 \\
\hline \multirow[t]{2}{*}{6} & $\mathrm{P}-2$ & 2.6 & 2.7 & 2.6 \\
\hline & Average & -0.15 & -0.25 & -0.20 \\
\hline 7 & $\mathrm{U}-1(\mathrm{ST})$ & $(-4.5)$ & $(-5,0)$ & $(-4.8)$ \\
\hline 8 & $\mathrm{U}-2(\mathrm{NTW})$ & 1.6 & --- & -- \\
\hline \multirow[t]{2}{*}{9} & $\mathrm{U}-2$ & 0.8 & 0.8 & 0.8 \\
\hline & Average & 1.2 & & \\
\hline 10 & $\mathrm{~S}-1(\mathrm{ST})$ & $(-5.2)$ & $(-5,0)$ & $(-5.1)$ \\
\hline 11 & $S-2$ & 5.2 & 5.2 & 5.2 \\
\hline 12 & $\mathrm{~V}-1(\mathrm{NTW})$ & 2.9 & --- & -- \\
\hline 13 & $\mathrm{~V}-2(\mathrm{NTW})$ & 3.2 & $\ldots$ & --- \\
\hline & Average & $\overline{3.05}$ & & \\
\hline \multicolumn{2}{|c|}{ Averages (w/o $U-1 \& S-1$ ) } & 1.2 & 0.6 & 0.8 \\
\hline
\end{tabular}

Key to Trucks

$$
\begin{aligned}
\mathrm{P} & =\text { Panel Truck } \\
\mathrm{U} & =\text { Pickup Truck } \\
\mathrm{S} & =\text { Step Van } \\
\mathrm{V} & =14^{\prime} \text { Van } \\
\mathrm{ST} & =\text { Snow Tires } \\
\text { NTW } & =\text { No Tenth Wheel }
\end{aligned}
$$


Appendix III

PROPOSED

OWM SPECIFICATIONS

FOR

"FIFTH-WHEEL" TESTING EQUIPMENT

1. General. --This specification describes a precision distancemeasuring device to be used by weights and measures officials for the testing of odometers and taximeters.

1. 1. Material. --The material to be used in the construction of this device shall be such as to provide strength, durability, corrosion resistance, and permanence.

1.2. Design. --The design of this device shall be such as to provide permanence, accuracy, ease of use, and maintenance-free operation.

1.3. Components. - -The device shall include the wheel assembly, frame, bumper mounting clamp, tension springs, and a distance-indicating system.

2. Wheel Assembly. - The wheel assembly shall consist of a tire, a rim, spokes, hubs, and bearings, and shall be mounted in a suitable frame (see 3.).

2.1. Tire.--A 26-inch $\times 2$ 2125-inch bicycle-type tire shall be used. It shall be carefully selected for good balance and run-out characteristics.

2.2. Rim.--A heavy-duty bicycle-type rim shall be used. It shall be carefully balanced.

2.3. Spokes.--Thirty-six spokes of 105 gage shall be used.

2. 4. Bearings. --Large-diameter, heavy-duty, double-row, sealed ball bearings shall be used. They shall be essentially frictionless. 
3. Frame. - The frame shall be constructed of a very strong, fairly lightweight material which shall provide a rigid support for the wheel. It shall also provide for the installation and operation of the tension springs, the bumper clamp, and the distanceindicating system.

4. Bumper Clamp. --The bumper clamp shall provide for the attachment of the frame to rear bumper of various vehicles. It shall be of universal design or shall be supplied with various adapters so that it will be susceptible of being attached to the majority of automobile bumpers in use today.

5. Tension Springs. --A matched pair of springs shall be included in the design of the device and shall be attached to the frame in such a manner as to provide a constant pressure of the tire on smooth roads. The springs may also be used to hold the device in a vertical position when not in use.

6. Distance-Indicating System.--A distance-indicating system shall be provided which will accurately indicate distance in thousandths $(0.001)$ of a mile, up to 9.999 miles, at speeds up to 55 miles per hour. It shall be provided with a 20 -foot connecting cable to allow the indicator to be located near the driver's wheel of the vehicle under test.

If the indicating device is electrical, it shall be powered by a 12 -volt source, and adapters shall be included which will allow the use of the vehicle cigarette lighter socket and any other 12 -volt power source.

If the indicating device is mechanical, it shall be lubricated for life and shall be provided with rotation arrows permanently attached to each end of the cable. A dial indicator may be used to indicate thousandths of a mile, but a digital indicator shall be used for the hundredths, tenths, and unit miles.

7. Warning Device. --A warning light (flashing light) or flag shall be provided which will be securely mounted 4 feet above the ground. If a flag is used, the bracket shall be mounted on springs. Provision shall be made to allow the wheel to be placed in a nearly vertical position for transport purposes. 
Appendix IV

\section{PROPOSED}

\section{OWM SPECIFICATIONS FOR SIMULATED-ROAD TESTING EQUIPIENT}

1. General.--This specification describes a precision distancemeasuring device to be used in simulated-road tests by weights and measures officials in the testing of odometers and taximeters.

1. 1. Material. --The material to be used in the construction of this device shall be such as to provide strength, durability, corrosion resistance, and permanence.

1.2. Design. --The design of this device shall be such as to provide permanence, accuracy, ease of use, and maintenance-free operation.

1.3. Components.--The device shall include a frame, at least two revolving cylinders, and a distanceindicating system.

2. Frame. --The frame shall be designed to accommodate for test purposes vehicles weighing up to 6,000 pounds with wheel bases of up to 132 inches (11 feet). It shall be designed and fabricated to provide for either recessed, permanent installation in a floor or temporary installation on a paved surface. If designed for the latter, it shall include approach ramps and be composed of 3 -foot sections, each susceptible to quick attachment, correct fitting, and easy handling. The frame shall include appropriate wheel guides to prevent the vehicle from sliding laterally.

3. Cylinders.--The cylinders shall be at least 34 inches wide and approximately 8 inches in diameter, with solid end caps and with solid steel shafting extending through the cylinders. The shafts are to be supported by heavy-duty bearings designed to accommodate the test loads with 20,000 hours minimum life expectancy. 
The front cylinder shaft shall be connected to a positive mechanical braking device which will allow the vehicle to leave the testing device. The rear cylinder shaft shall be precisely machined to provide accurate distance indications through an appropriate system.

4. Distance-Indicating System.--A distance-indicating system shall be provided which will indicate distance in thousandths $(0.001)$ of a mile, up to 9.999 miles, at speeds up to 55 miles per hour. It shall be provided with a 20 -foot connecting cable to allow the indicator to be located near the driver's wheel of the vehicle under test.

If the indicating device is electrical, it shall be powered by either a 115-volt or 12-volt source. If 12 -volt power is used, adapters shall be included which will allow the use of the vehicle cigarette lighter socket as well as any other 12 -volt source of power.

If the indicating device is mechanical, it shall be lubricated for life and shall be provided with rotation arrows permanently attached to each end of the cable. A dial indicator may be used to indicate thousandths of a mile, but a digital indicator shall be used for the hundredths, tenths, and unit miles. 



\section{THE NATIONAL BUREAU OF STANDARDS}

The scope of activities of the National Bureau of Standards at its major laboratories in Washington, D.C., and Boulder, Colorado, is suggested in the following listing of the divisions and sections engaged in technical work. ln general, each section carries out specialized research, development, and engineering in the field indicated by its title. A brief description of the activities, and of the resultant publications, appears on the inside of the front cover.

WASIIIGTON, D. C.

Electricity. Resistance and Reactance. Electrochemistry. Electrical Instruments. Magnetic Measurements. Dielectrics. High Voltage. Absolute Electrical Measurements.

Vetrology. Photometry and Colorimetry. Refractometry. Photographic Research. Length. Engineering Metrology. Vass and Volume.

Ileat. Temperature Physics. Heat Measurements. Cryogenic Physics. Equation of State. Statistical Physics. Radiation Physics. X-ray. Radioactivity. Radiation Theory. High Energy Radiation. Radiological Equipment. Nucleonic Instrumentatior. Neutron Physics.

Analytical and Inorganic Chemistry. Pure Substances. Spectrochemistry. Solution Chemistry. Standard Reference Materials. Applied Analytical Research. Crystal Chemistry.

Mechanics. So und. Pressure and Vacuum. Fluid Mechanics. Engineering Mechanics. Rheology. Combustion Controls.

Polymers. Macromolecules: Synthesis and Structure. Polymer Chemistry. Polymer Physics. Polymer Charac terization. Polymer Evaluation and Testing. Applied Polymer Standards and Research. Dental Research.

Metallurgy. Engineering Metallurgy. Metal Reactions. Metal Physics. Electrolysis and Metal Deposition. Inorganic Solids. Engineering Ceramics. Glass. Solid State Chemistry. Crystal Growth. Physical Properties. Crystallography.

Building Research. Structural Engineering. Fire Research. Mechanical Systems. Organic Building Materials. Codes and Safety Standards. Heat Transfer. Inorganic Building Materials. Metallic Building Materials.

Applied Mathematics. Numerical Analysis. Computation. Statistical Engineering. Mathematical Physics. Operations Research.

Data Processing Systems. Components and Techniques. Computer Technology. Measurements Automation. Engineering Applications. Systems Analysis.

Atomic Physics. Spectroscopy. Infrared Spectroscopy. Far Ultraviolet Physics. Solid State Physics. Elcctron Physics. Atomic Physics. Plasma Spectroscopy.

Instrumentation. Engineering Electronics. Electron Devices. Electronic Instrumentation. Mechanical lnstruments. Basic lnstrumentation.

Physical Chemistry. Thermochemistry. Surface Chemistry. Organic Chemistry. Molecular Spectroscopy. Elementary Processes. Mass Spectrometry. Photochemistry and Radiation Chemistry.

office of Weights and Measures.

BOLLDEK, COLO.

\section{CRYOGENIC ENGINEERING LABORATORY}

Cryogenic Processes. Cryogenic Properties of Solids. Cryogenic Technical Services. Properties of Cryogenic Fluids.

\section{CENTRAL RADIO PROPAGATION LABORATORY}

Ionosphere Research and Propagation. Low Frequcncy and Very Low Frequency Research. Ionosphere Research. Prediction Services. Sun-Earth Relationships. Field Engineering. Radio Warning Services. Vertical Soundings Research.

Troposphere and Space Telecommunications. Data Reduction lnstrumentation. Radio Noise. Tropospheric Measurements. Tropospheric Analysis. Spectrum Utilization Research. Radio-Meteorology. Lower Atmosphere Physics.

Rađio Systems. Applied Electromagnetic Theory. High Frequency and Very High Frequency Research. Frequency Utilization. Modulation Research. Antenna Rescarch. Radiodetermination.

Upper Atmosphere and Space Physics. Upper Atmosphere and Plasma Physics. High Latitude lonosphere Physics. lonosphere and Exosphere Scatter. Airglow and Aurora. lonospheric Radio Astronomy.

\section{RADIO STANDARDS LABORATORY}

Rađio Standards Physics. Frequency and Time Disseminations. Radio and Microwave Materials. Atomic Fre quency and Time-lnterval Standards. Radio Plasma. Microwave Physics.

Radio Standards Engineering. High Frequency Electrical Standards. High Frequency Calibration Services. High Frequency Impedance Standards. Microwave Calibration Services. Microwave Circuit Standards. Low Frequency Calibration Services.

Joint Institute for Laboratory Astrophysics-NBS Group (Univ. of Colo.). 
NBS 